\title{
Objective measurement of refractive errors: Comparison of plusoptix s08 with a standard autorefractometer
}

\author{
Objektif refraksiyon kusuru ölçümü: Plusoptix s08 ile standart bir otorefraktometrenin \\ karşılaştırılması
}

\author{
Soner Demirel ${ }^{1}$, Şemsettin Bilak ${ }^{2}$, İsa Yuvacl ${ }^{3}$, Tongabay Cumurcu ${ }^{1}$, Cemil Çolak
}

\begin{abstract}
Objective: Comparison of Plusoptix S08 with a standart autorefractometer (Topcon RM 8000B) in children and adults.

Methods: 220 eyes of 110 children, with a mean age of $8.06 \pm 2.89$ years old were examined to compare noncycloplegic measurements provided by Plusoptix S08 and cycloplegic measurements provided by Topcon RM8000B autorefractometer. In addition, 254 eyes of 127 adults, with a mean age of $33.3 \pm 13.36$ years old were examined to compare non-cycloplegic refractive measurements provided by Plusoptix S08 and Topcon RM $8000 \mathrm{~B}$ autorefractometer. All measurements were repeated three times. Median sphere, cylinder, spherical equivalent and cylindrical axes as Jackson cross cylinder power measurements (J0 and J45) were compared statistically.
\end{abstract}

Results: The median differences in spheres, cylinders, spherical equivalents, J0 and J45 powers were -0.25 $D(P<0.001),-0.25 D(P<0.001),-0.25 D(P<0.001)$, $-0.02(P=0.038), 0.00(P=0.395)$, in children, respectively. These values were $0.50(P<0.001), 0.00(P<0.001)$, 0.375 ( $P<0.001), 0.03(P=0.053), 0.79(P=0.081)$, in adults, respectively.

Conclusion: Plusoptix S08 has a myopic misspelled according to Topcon-RM8000B autorefractometer in children. However, measurements provided with Plusoptix S08 were more hyperopic than those with Topcon RM8000B autorefractometer in adults. J Clin Exp Invest 2013; 4 (1): 40-46

Key words: Refractive errors, autorefraction, photorefraction, plusoptix S08

\section{ÖZET}

Amaç: Çocuklarda ve erişkinlerdeki refraksiyon kusuru ölçümünde, Plusoptix S08 ile standart bir oto refraktometre (Topcon RM 8000B) ölçümlerinin karşılaştırılması.

Yöntemler: Yaş ortalaması $8.06 \pm 2.89$ yıl olan 110 çocuğun 220 gözü Plusoptix S08 ile sikloplejisiz olarak, Topcon RM-8000B otorefraktometresiyle sikloplejili olarak ölçüldü. Elde edilen değerler karşılaştırıldı. Ayrıca, yaş ortalaması 33,3 \pm 13,4 olan 127 yetişkinin 254 gözü, Plusoptix S08 ve Topcon RM 8000B otorefraktometre ile sikIoplejisiz olarak ölçülerek, bu ölçümlerin karşılaştırması yapıldı. Tüm ölçümler üç kez tekrarlandı. Ortalama sferik, silindirik, sferik ekivalan ve silindirik aks değerleri istatistiksel olarak karşılaştırıldı.

Bulgular: Ortalama sferik, silindirik, sferik ekivalan, J0 ve J45 güçleri çocuklarda sırasıyla: $-0.25 \mathrm{D}(\mathrm{p}<0.001)$, $-0.25 D(p<0.001),-0.25 D(p<0.001),-0.02(p=0.038)$, $0.00(p=0.395)$ bulundu. Erişkinlerde ise $0.50(p<0.001)$, 0.00 ( $p<0.001), 0.375(p<0.001), 0.03(p=0.053), 0.79$ $(p=0.081)$ olarak ölçüldü.

Sonuç: Topcon-RM8000B otorefraktometreye göre Plusoptix S08 çocuklarda daha miyopik bir ölçüm yapmaktaydı. Ancak yetişkinlerdeki Plusoptix S08 ölçümleri daha hipermetropik izlenmekteydi.

Anahtar kelimeler: Refraksiyon kusuru, plusoptix S08, fotorefraksiyon, otorefraksiyon

${ }^{1}$ Department of Ophthalmology, Inönü University, Faculty Of Medicine, Malatya, Turkey

${ }^{2}$ Department of Ophthalmology, Adıyaman University, Faculty Of Medicine, Adıyaman, Turkey

${ }^{3}$ Department of Ophthalmology, Kayseri Education and Research Hospital, Kayseri, Turkey

${ }^{4}$ Department of Biostatistics, Inönü University, Faculty Of Medicine, Malatya, Turkey

Correspondence: Soner Demirel,

İnönü University, Faculty of Medicine, Department of Ophthalmology, Malatya, Turkey Email: sonerdem2000@yahoo.com

Received: 26.12.2012, Accepted: 28.01.2013

Copyright (C) JCEI / Journal of Clinical and Experimental Investigations 2013, All rights reserved 


\section{INTRODUCTION}

Cycloplegic retinoscopy and subjective refraction is still the gold standard for measuring refractive error in children. But, cycloplegia usage take more time and causes patient discomfort. Therefore, autorefractometers have become widely used to determine the objective refractive status. Modern autorefractometers are standard clinical instruments that generally use Scheiner's double pinhole principle (e.g. Topcon RM-8000B, Topcon Corporation- Tokyo, Japan) or retinoscopy based infrared video refraction method (e.g. Plusoptix S08 - Plusoptix $\mathrm{GmbH}$, Nuremberg, Germany). ${ }^{1-3}$ In addition, few autorefractometers work on slightly different principals. Such as, Grand Seiko/Shin-Nippon (Grand Seiko Co., Ltd., Fukuyama, Japan) works on the principal of imaging the magnification of a shape reflected from the retina and Canon R-1 (Canon Inc., Tokyo, Japan) works on position of the peak intensity of light as a lens passed through three beams of light reflected off the retina. ${ }^{4}$ Currently, some videorefractors were presented by manufacturers as non-cycloplegic autorefractometers called as photoscreener.

Photorefraction is described as retinoscopy based videorefraction method to determine refractive state from a distance of a meter or more without cycloplegia. Photorefraction method is preferred by Kennedy and Schmidt et al to screen children or children who would not otherwise cooperate with objective pediatric vision screening methods; however its reliability and accuracy has been questioned. Other commercial devices that have used this measurement principle include: iScreen Vision, MTI PS-100 Photoscreener, PlusOptix S08 AutoRefractor/Photoscreener (Previous models were PowerRefractor and Plusoptix S04, current version is S09), Right Medical Retinomax Autorefractor, Visiscreen OSS-C, Welch Allyn SureSight Autorefractor, Fortune Optical VRB-100 videophotorefractor. ${ }^{5-8}$

Various studies suggest that non-cycloplegic photorefraction has reasonable accuracy and repeatability compared with cycloplegic retinoscopy and subjective refraction. However, in a study it was demonstrated that accommodation may not be completely neutralized. ${ }^{3}$ It may be especially important in children who have high accommodative reserve.

PlusoptiX S08 (Plusoptix GmbH, Nuremberg, Germany) is a new non-cycloplegic infrared videoretinoscopy based photorefractor. It can measure the refractive status binocularly, which facilitates the detection of anisometropia, at a distance of approximately 1 meter in dim room. Refractive status is determined by assessing the distribution of the reflected light from retina across the pupil. According to its user manual, it has maximum spherical and cylindrical range of -7.00 to $+5.00 \mathrm{D}$. 9-11 $^{-11}$

Instead of easy usage and fast measurement technique, there were also some difficulties experienced in the measurement of especially children in standart autorefractometers. For this reason, some new devices have been developed recently, which can measure from a distance, such as Plusoptix S08.

There are many studies about comparison of photoscreeners, autorefractometers and/or gold standard retinoscopy. In previous studies, the measurements of autorefractometers were compared with retinoscopy. Though their measurement were not found exactly correct, found compatible with retinoscopy. ${ }^{1,3,12-14}$ Based on this information, we just aimed to investigate the correlation of measurements provided by Plusoptix $\mathrm{S} 08$ and a standard autorefractor (it was Topcon RM-8000B in our clinic), not to investigate the accuracy of Plusoptix S08. The main question was "May Plusoptix S08 considered as a standard autorefractor?"

\section{METHODS}

Two hundred twenty eyes of 110 children (47 male and 63 female), with a mean age of $8.06(S D=2.89)$ years (range from 1 to 13 years, median 8.0 years) were examined. At first, non-cycloplegic measurements with Plusoptix S08 were performed, and then cycloplegic refraction was obtained with Topcon RM 8000B autorefractometer.

Non-cycloplegic measurements with Plusoptix S08 and Topcon RM 8000B autorefractometer of 254 eyes of 127 adults (66 male and 61 female), with a mean age of age $33.3(S D=13.36)$ years (range from 17 to 70 years, median 30.0 years) were performed.

Approval to conduct the study was obtained from local ethic committee of Inonu University. All patients underwent a complete ophthalmologic examinationto minimize the measurement errors, subjects with ocular pathologies (strabismus, amblyopia, significant refractive error or history of ocular surgery) and abnormal binocular vision were excluded from the analyses. Measurements were repeated three times with new calibrated equipments by only one ophthalmologist. Cycloplegia was induced by 2 drops of cyclopentolate $1 \%$ administered with 5 minutes intervals to both eyes. After an hour, if pupillary constriction was still present, a third drop was administered. Cycloplegia was considered complete if the pupil dilated $6 \mathrm{~mm}$ and pupillary constriction was absent. ${ }^{15,16}$ 
Median of spherical values (S), spherical equivalent $(\mathrm{SE}=$ sphere + [cylinder/2), cylindrical values (C) and axises were statistically compared. But assessing the variance in the astigmatic component poses a problem in conventional form, mean sphere, cylinder and axis component were converted into a vector representation for analysis described by Thibos et al: (spherical equivalent= sphere + [cylinder/2]); Jackson cross cylinder at axis $0^{\circ}$ (J0) with power $\mathrm{JO}=(-2$ [cylinder/2. Cos [2.axis] $)$; Jackson cross cylinder at axis $45^{\circ}$ (J45) with power J45= (-2[cylinder/2. $\sin [2$.axis] $) .{ }^{17}$

The normality of our data was tested with Shapiro-Wilks test and because the normality assump- tion was not satisfied Wilcoxon signed rank test was used for the comparision of Plusoptix S08 and Topcon RM 8000B measurements. The significance level ( $p$ value) is chosen to be less than 0.05 . The comparisons between measures of spherical and cylindrical values were presented graphically using Bland-Altman plots.

\section{RESULTS}

The median (with minimum and maximum range) of sphere, cylinder, spherical equivalent (SE), J0 and J45 power measurements for Plusoptix S08 and Topcon RM 8000B autorefractor were shown in Table 1 and Table 2.

Table 1. Noncycloplegic measurements with Plusoptix S08 and cycloplegic measurements with Topcon RM8000B autorefractometer in children. Min= Minimum value, Max= Maximum value, $D=$ Dioptri

\begin{tabular}{llll}
\hline Measurements of adults & $\begin{array}{l}\text { PLUSOPTIX S08 } \\
\text { Median (min / max })\end{array}$ & $\begin{array}{l}\text { TOPCON RM 8000B } \\
\text { Median (min / max) }\end{array}$ & $\mathrm{P}^{\times}$ \\
\hline Spherical (D) & $+0.50(-4.00 /+3.50)$ & $0.00(-3.75 /+2.50)$ & $<0.001$ \\
Cylindrical (D) & $-0.50(-5.50 / 0.00)$ & $-0.50(-4.50 / 0.00)$ & $<0.001$ \\
Spherical Equivalent & $0.125(-5.25 /+3.25)$ & $-0.25(-5.37 /+2.12)$ & $<0.001$ \\
$0^{\circ}$ Jackson & $-0.02(-1.44 /+1.86)$ & $-0.05(-2.11 /+1.23)$ & 0.053 \\
$45^{\circ}$ Jackson & $-0.04(-2.64 /+1.93)$ & $-0.83(-2.16 /+1.30)$ & 0.081 \\
\hline
\end{tabular}

Table 2. Noncycloplegic measurements with Plusoptix S08 and noncycloplegic measurements with Topcon RM8000B autorefractometer in adults. Min= Minimum value, Max= Maximum value, $D=$ Dioptri

\begin{tabular}{|c|c|c|c|}
\hline $\begin{array}{l}\text { Measurements } \\
\text { of children }\end{array}$ & $\begin{array}{l}\text { PLUSOPTIX S08 } \\
\text { Median (min / max) }\end{array}$ & $\begin{array}{l}\text { TOPCON RM 8000B } \\
\text { Median (min / } \max )\end{array}$ & $\mathrm{P}$ \\
\hline Spherical (D) & $+1.25(-5.75 /+4.75)$ & $+1.50(-4.25 /+5.50)$ & 0.001 \\
\hline Cylindrical (D) & $-0.75(-5.75 / 0.00)$ & $-0.50(-4.75 / 0.00)$ & $<0.001$ \\
\hline Spherical Equivalent & $+1.00(-6.00 /+4.63)$ & $+1.25(-4.75 /+4.63)$ & $<0.001$ \\
\hline $0^{\circ}$ Jackson & $0.01(-2.75 /+2.35)$ & $0.03(-1.99 /+1.81)$ & 0.038 \\
\hline $45^{\circ}$ Jackson & $-0.03(-2.38 /+1.80)$ & $-0.03(-2.10 /+2.28)$ & 0.395 \\
\hline
\end{tabular}

\section{Sphere}

The median spherical value was +1.25 (ranging, $-5.75 /+4.75$ ) dioptri (D) with Plusoptix S08 and 1.50 (ranging, $-4.25 /+5.50$ ) D with Topcon autorefractometer in children. Plusoptix S08 has a miyopic tendency in children. The median spherical values were +0.50 (ranging, $-4.00 /+3.50$ ) D with Plusoptix S08 and 0.00 (ranging, $-3.75 /+2.50$ ) D with Topcon autorefractometer in adults. Measurements provided with Plusoptix S08 were more hyperopic in adults. There were statistically significant differences in children and adults $(p<0.001)$ (Figure 1 and 2).

\section{Cylinder}

In children, the median cylindrical values were -0.75 (ranging, -5.75 / 0.00) D with Plusoptix S08 and -0.50 (ranging, $-4.75 / 0.00$ ) D with topcon autorefractometer.

In adults, the median cylindrical value was -0.50 (ranging, $-5.50 / 0.00$ ) D with Plusoptix S08 and -0.50 (ranging, -4.50 / 0.00) D with Topcon autorefractometer. There were statistically significant differences in these variables in both groups ( $p<$ 0.001 ) (Figure 3 and 4). 

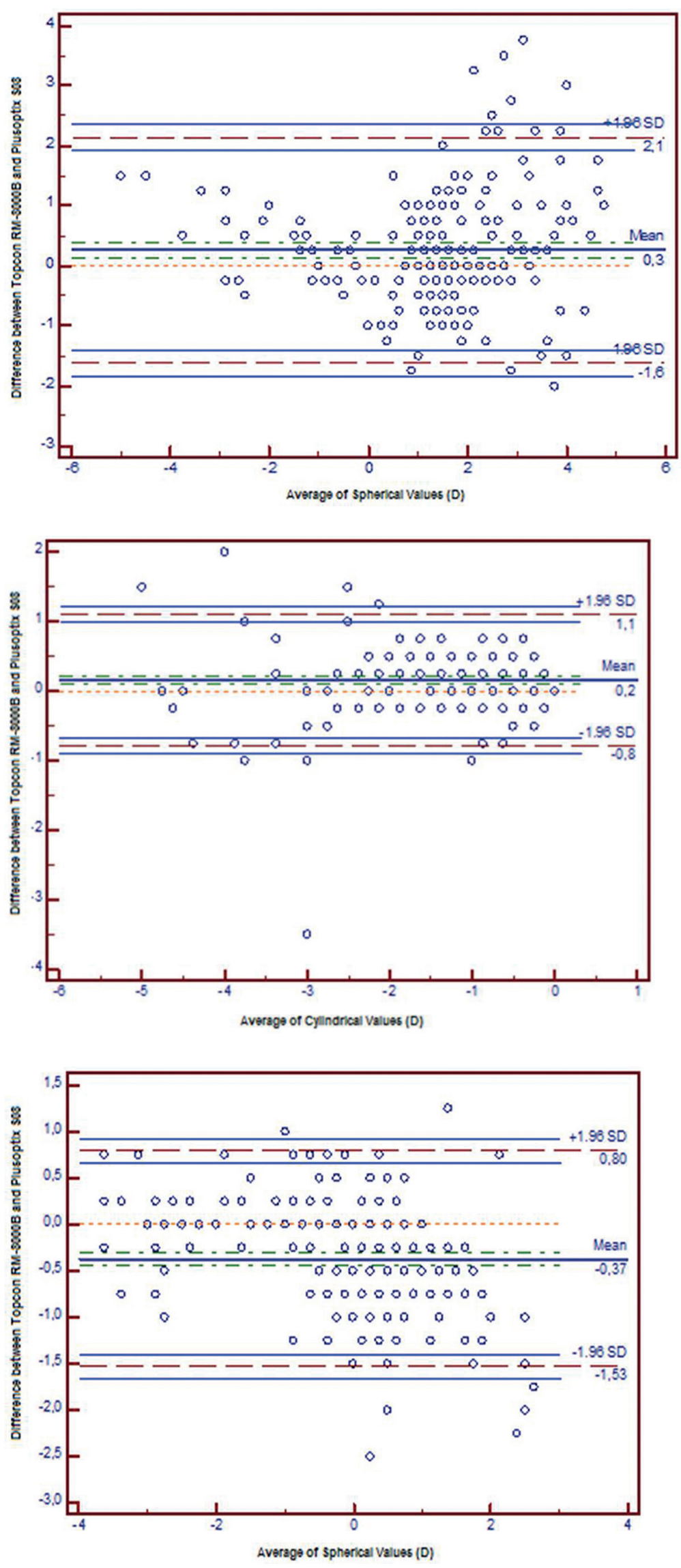

Figure 1. Difference between Topcon RM-8000B and Plusoptix S08 in Spheric components (D) using Bland-Altman plot in children.

Figure 2. Difference between Topcon RM8000B and Plusoptix S08 in Cylindrical components (D) using Bland-Altman plot in children.

Figure 3. Difference between Topcon RM8000B and Plusoptix S08 in Spheric components (D) using Bland-Altman plot in adults. 


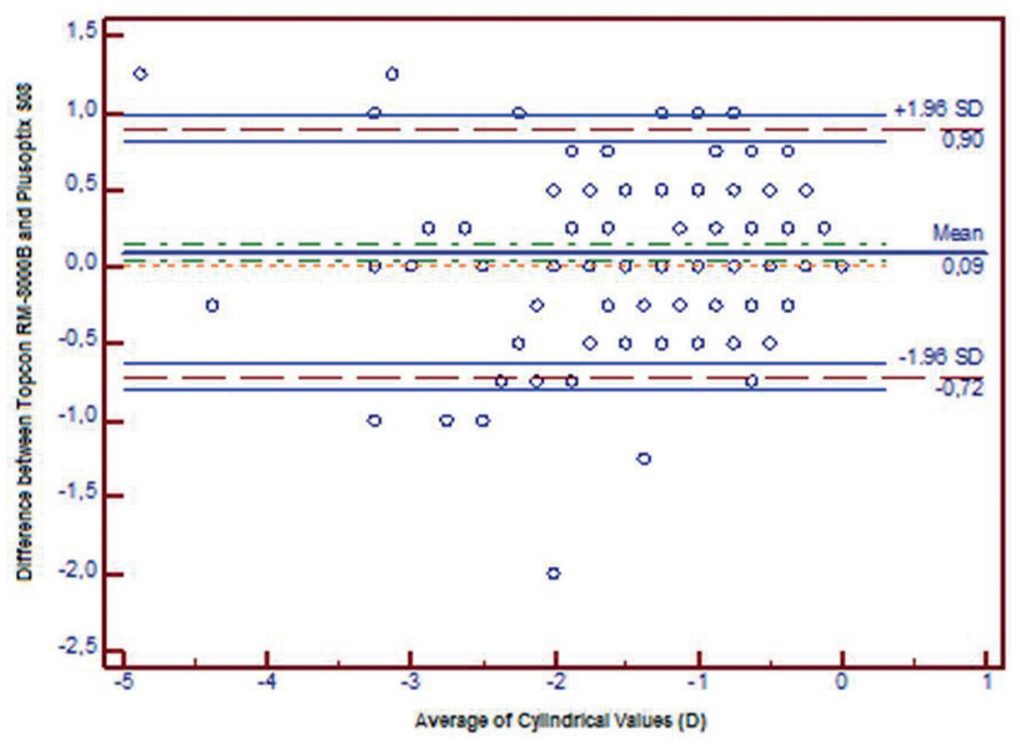

Figure 4. Difference between Topcon RM-8000B and Plusoptix S08 in Cylindrical components (D) using Bland-Altman plot in adults.

\section{Spherical Equivalent}

In children: The median SE values were +1.00 (ranging, $-6.00 /+4.63$ ) D with Plusoptix S08 and +1.25 (ranging, $-4.75 /+4.63$ ) $D$ with Topcon autorefractometer.

In adults: The median SE was +0.125 (ranging, $-5.25 /+3.25)$ D with Plusoptix S08 and -0.25 (ranging, $-5.37 /+.12$ ) D with Topcon autorefractometer.

Statistically significant differences were observed $(p<0.001)$ in both groups.

\section{$\mathrm{J} 0$ and $\mathrm{J} \mathbf{4 5}$ powers}

In children: The median J0 powers were -0.01 (ranging, $-2.75 /+2.35$ ) D with Plusoptix S08 and 0.03 (ranging, $-1.99 /+1.81$ ) D with Topcon autorefractometer. The median J45 powers were -0.03 (ranging, $-2.38 /+1.80$ ) D with Plusoptix S08 and -0.03 (ranging, $-2.10 /+2.28$ ) D with Topcon autorefractometer.

In adults: The median $\mathrm{J} 0$ powers were -0.02 (ranging, -1.44 / +1.86) D with Plusoptix S08 and -0.05 (ranging, $-2.11 /+1.23$ ) D with Topcon autorefractometer. The median J45 powers were -0.04 (ranging, -2.64 / +1.93) D with Plusoptix S08 and -0.83 (ranging, $-2.16 /+1.30$ ) $D$ with Topcon autorefractomoeter.

Although, in terms of J0 power, statistically significant difference was observed in children $(p=$ 0.038 ), no difference was observed in adults ( $p=$ 0.353 ). Moreover, in terms of J45 power, no significant difference was noticed in children $(p=0.395)$ or adults $(p=0.081)$.

\section{DISCUSSION}

Cycloplegic retinoscopy and subjective refraction is still the gold standard for measuring refractive error in children. But autorefractometers have become widely used to measure of refractive status. Major advantages of PlusoptiX S08 photorefraction when compared to autorefractometers are that it can be performed at a distance and it provides simultaneous measurements of both eyes therefore; it is especially suitable for infants or non-cooperative patients and pediatric vision screen. Major disadvantages of photorefractors are its limited ability to measure range and questionable repeatability and accuracy. $3,12,16$

In the literature, we have seen few studies designed to compare the measurements Plusoptix $\mathrm{S} 08$ and an autorefractometer in children and adults..$^{13-21}$ Aim of the study was to evaluate if Plusoptix S08 could be considered as an autorefractometer or not.

We found that, Plusoptix S08 had a myopic misspelt in children $(-0.25 \mathrm{D})$ but it showed hyperopic results (+0.50 D) in adults; both results were statistically significant. Similar to spherical values, SE were also observed a slight myopic tendency $(-0.25 \mathrm{D})$ in children while hyperopic tendency in adults (+0.375). In addition, cylindrical values measured with Plusoptix S08 were more negative in both groups. While cylindrical values measured by both devices were not statistically compatible with each other; all Jackson cross cylinder powers except J0 power in children were compatible.

Allen et al. was reported no significant difference between the previous model of Plusoptix S08 called PowerRefractor and Nidek AR 600-A autore- 
fractor measurements in adults[18]. Choi et al. compared the PowerRefractor to a modern autorefractor (Nidek AR800) and the results showed good agreement between autorefractor and Power-Refractor in adults. Hovewer in children aged 3-6 years; the PowerRefractor gave slightly more hyperopic readings than the autorefractor. ${ }^{19}$

In contrast to our results, in a study which compare PowerRefractor with Shin-Nippon SRW-5000 autorefractometer, Hunt et al identified that PowerRefractor results were more negative than SRW5000 in non-cycloplegic adults. As a result of their study, PowerRefractor was suggested as a useful objective screening instrument. ${ }^{20}$

To evaluate the viability of the PowerRefractor as a screening tool, the data provided by the PowerRefractor and an autorefractor or retinoscopy (Topcon RM-A2000) were compared for 150 children aged from 6 months to 5 years. Abrahamsson et al declared 1D difference in spherical equivalent measurements between the Powerrefractor and Topcon RM-A2000 in 142 children. In addition, the PowerRefractor was reported insufficient in clinical situation for estimating the amount and axis of astigmatism. ${ }^{21}$

In two different studies of Matta et al., Plusoptix S04 was also reported as an effective screening tool, because it was found a useful tool for the detection of amblyopia risk factors and showed a high sensitivity of $98.9 \%$ and specificity of $96.1 \% .^{12,22}$

Paff et al. evaluated the performance of a hand held autorefractor and PlusoptiX S08 in measuring refractive errors as a vision screener by comparing them with cycloplegic retinoscopy (CR) of 200 children. When compared to CR, the PlusoptiX S08 showed a mean difference of $-1.13 \pm 1.25 \mathrm{D}$ for spherical equivalent (SE) and $-0.23 \pm 0.53 \mathrm{D}$ for the cylinder; after cycloplegia $-2.11 \pm 1.64 \mathrm{D}$ for SE and $-0.06 \pm 0.47 \mathrm{D}$ for the cylinder were measured. They concluded that, PlusoptiX S08 has high sensitivity for the detection of myopia, astigmatism and anisometropia compared to cycloplegic retinoscopy; however, when used without cycloplegia, hyperopia is underestimated. ${ }^{9}$

Arıcı et al. compared the refractive errors measured with Plusoptix S08 photorefractometer, Nidek ARK-30 hand-held autorefractometer and Potec PRK-6000 autorefractometer in school-age children and adult population. ${ }^{23}$ They found statistically significant difference in spherical power and spherical equivalent measured by the three devices $(p<0.05)$, but there was no significant difference in cylindrical values $(p=0.641, p=0.431$, respectively) and
Jackson cross cylinder powers at $0^{\circ}$ and $45^{\circ}$ axis $(p>0.05)$ in both groups.

Consequently, we observed statistically significant difference between the measurements of Plusoptix S08 and a standard autorefractometer. On the other hand, it should also be indicated about ophthalmologic use of PlusoptixS08 that, it is a good guide for the measurement of refractive errors in children and non-cooperative people, but inaccurate for prescribing lenses.

\section{REFERENCES}

1. Pesudovs K, Weisinger HS. A comparison of autorefractor performance. Optom Vis Sci 2004;81:554-558.

2. Hodi S, Wood IC. Comparison of the techniques of videorefraction and static retinoscopy in the measurement of refractive error in infants. Ophthalmic Physiol Opt 1994;14:20-24.

3. Choong YF, Chen AH, Goh PP. A comparison of autorefraction and subjective refraction with and without cycloplegia in primary school children. Am J Ophthalmol 2006;142:68-74.

4. Davies LN, Mallen EA, Wolffsohn JS, Gilmartin B.Clinical evaluation of the Shin-Nippon NVision-K 5001/Grand Seiko WR-5100K autorefractor. Optom Vis Sci 2003;80:320-324.

5. Kennedy RA, Thomas DE. Evaluation of the iScreen digital screening system for amblyogenic factors. Can J Ophthalmol 2000;35:258-262.

6. Schmidt P, Maguire M, Dobson V, et al. Vision in Preschoolers Study Group. Comparison of preschool vision screening tests as administered by licensed eye care professionals in the Vision In Preschoolers Study. Ophthalmology 2004;111:637-650

7. Cooper CD, Gole GA, Hall JE, et al. Evaluating photoscreeners II: MTI and fortune videorefractor. Aust N Z J Ophthalmol 1999;27:387-398.

8. Schmucker C, Grosselfinger R, Riemsma R, et al. Diagnostic accuracy of vision screening tests for the detection of amblyopia and its risk factors: a systematic review. Graefes Arch Clin Exp Ophthalmol 2009;247:1441-1454.

9. Paff T, Oudesluys-Murphy AM, Wolterbeek R, et al. Screening for refractive errors in children: the PlusoptiX S08 and the Retinomax K-plus2 performed by a lay screener compared to cycloplegic retinoscopy. J AAPOS 2010;14:478-483.

10. Schaeffel F, Mathis U, Brüggemann G. Noncycloplegic photorefractive screening in pre-school children with the "PowerRefractor" in a pediatric practice. Optom Vis Sci 2007;84:630-639.

11. Howland HC. Photorefraction of eyes: history and future prospects. Optom Vis Sci 2009;86:603-606

12. Matta NS, Arnold RW, Singman EL, Silbert DI. Comparison between the Plusoptix and MTI Photoscreeners. Arch Ophthalmol 2009;127:1591-1595. 
13. Erdurmuş $M$, Yagci R, Karadag $R$, et al. A comparison of photorefraction and retinoscopy in children. J AAPOS 2007;11:606-611.

14. Rotsos T, Grigoriou D, Kokkolaki A, et al. A comparison of manifest refractions, cycloplegic refractions and retinoscopy on the RMA-3000 autorefractometer in children aged 3 to 15 years. Clin Ophthalmol 2009;3:429-431.

15. Zhao J, Mao J, Luo R, et al. Accuracy of noncycloplegic autorefraction in school-age children in China. Optom Vis Sci 2004;81:49-55.

16. Lai YH, Tseng HY, Hsu HT, Chang SJ, Wang HZ. Uncorrected visual acuity and noncycloplegic autorefraction predict significant refractive errors in taiwanese preschool children. Ophthalmology 2013;120:271276.

17. Thibos LN, Horner D. Power vector analysis of the optical outcome of refractive surgery. J Cataract Refract Surg 2001;27:80-85

18. Allen PM, Radhakrishnan H, O'Leary DJ. Repeatability and validity of the PowerRefractor and the Nidek AR600-A in an adult population with healthy eyes. Optom Vis Sci. 2003;80:245-251.
19. Choi M, Weiss S, Schaeffel F, et al. Laboratory, clinical, and kindergarten test of a new eccentric infrared photorefractor (PowerRefractor). Optom Vis Sci 2000;77:537-548.

20. Hunt OA, Wolffsohn JS, Gilmartin B. Evaluation of the measurement of refractive error by the PowerRefractor: a remote, continuous and binocular measurement system of oculomotor function. $\mathrm{Br} \mathrm{J}$ Ophthalmol 2003;87:1504-1508.

21. Abrahamsson M, Ohlsson J, Björndahl M, et al. Clinical evaluation of an eccentric infrared photorefractor: the PowerRefractor. Acta Ophthalmol Scand 2003;81:605-610.

22. Matta NS, Singman EL, Silbert DI. Performance of the Plusoptix vision screener for the detection of amblyopia risk factors in children. J AAPOS 2008;12:490492.

23. Arıcı C, Türk A, Ceylan OM, et al. Comparison of refractive errors measured by Plusoptix S08, Potec PRK-6000 and Nidek ARK-30 hand-held autorefractometer in school age children and adult population. Turk J Ophthalmol 2010;40:328-332. 